\title{
Antioxidation Mechanism of Highly Concentrated Electrolytes at High Voltage
}

\section{Supporting Information}

Xiaoling Cui ${ }^{1,2,3}$, Jingjing Zhang ${ }^{1}$, Jie Wang ${ }^{1}$, Peng Wang ${ }^{1}$, Jinlong Sun ${ }^{1}$, Hong Dong ${ }^{1}$, Dongni Zhao ${ }^{1,2,3}$, Chunlei Li ${ }^{1,2,3}$, Shuxiang Wen ${ }^{1}$, Shiyou $\mathrm{Li}^{* 1,2,3}$

${ }^{1}$ School of Petrochemical Technology, Lanzhou University of Technology, Lanzhou 730050, P.R. China

${ }^{2}$ Key Laboratory of Low Carbon Energy and Chemical Engineering of Gansu Province, Lanzhou 730050, P.R. China

${ }^{3}$ Gansu Engineering Laboratory of Cathode Material for Lithium-ion Battery, Lanzhou 730050, P.R. China 

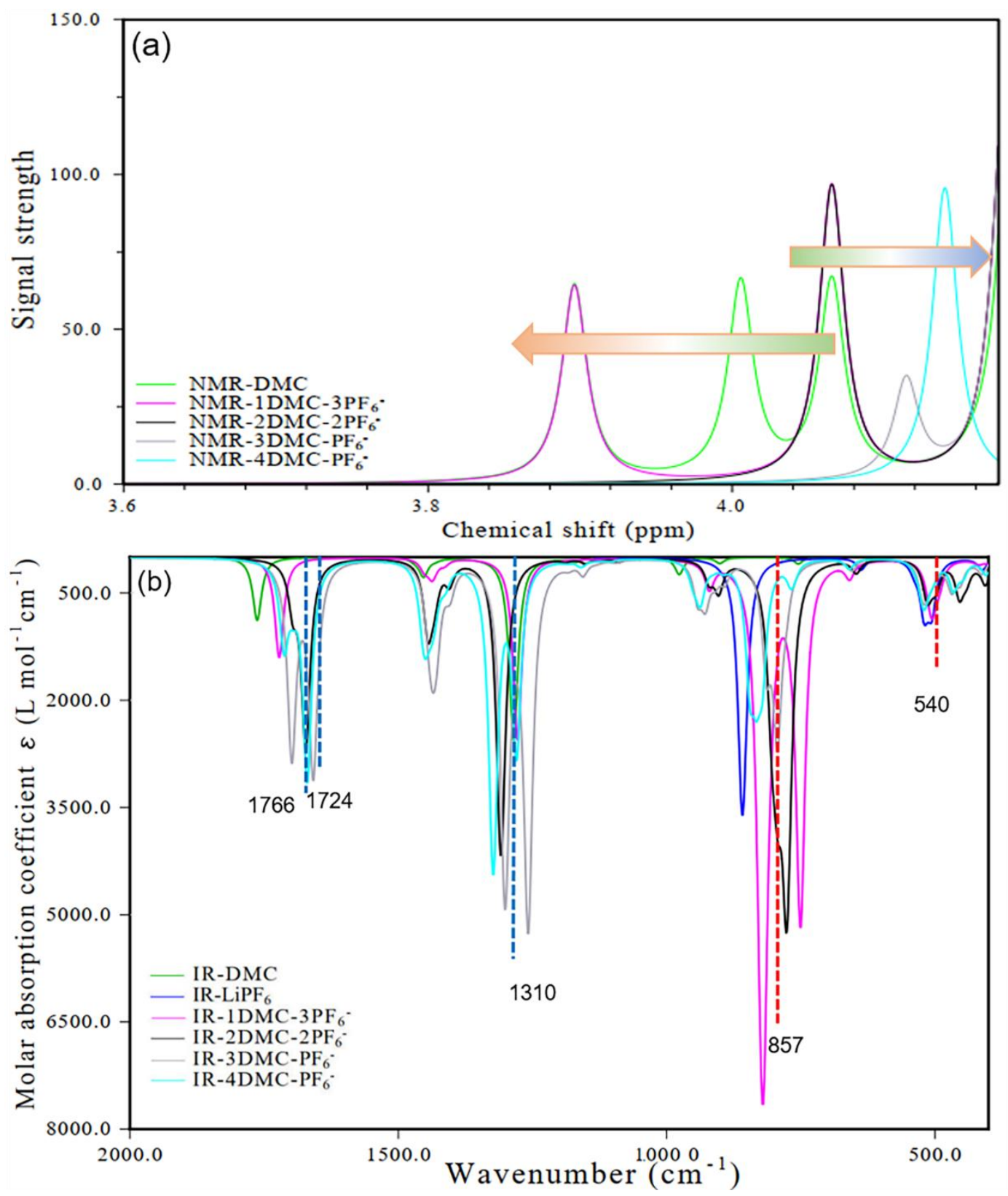

Figure S1. Quantum Chemical Calculation of Electrolyte System with Different Concentrations. (a) ${ }^{1} \mathrm{H}-\mathrm{NMR}$ spectra; (b) Infrared Spectra.

${ }^{1} \mathrm{H}-\mathrm{NMR}$ and IR spectra are performed using Gaussian 16 package. The combination of B3LYP and $6-311+\mathrm{G}(2 \mathrm{~d}, \mathrm{p})$ groups is used for structural optimization, frequency analysis and single point energy calculation. Software of Multiwfn 3.8 combined with VMD1.9.3 was used for ${ }^{1} \mathrm{H}-\mathrm{NMR}$ and IR spectra with a correction factor of 0.9614 . The results indicate the theoretical results are consistent 
with the experimental results. That is, ${ }^{1} \mathrm{H}-\mathrm{NMR}$ showed that the chemical shift of dilute concentration electrolyte shifted to high field and that of highly concentrated electrolyte to low field. The characteristic peaks of the infrared spectrum are also consistent with the experimental results.
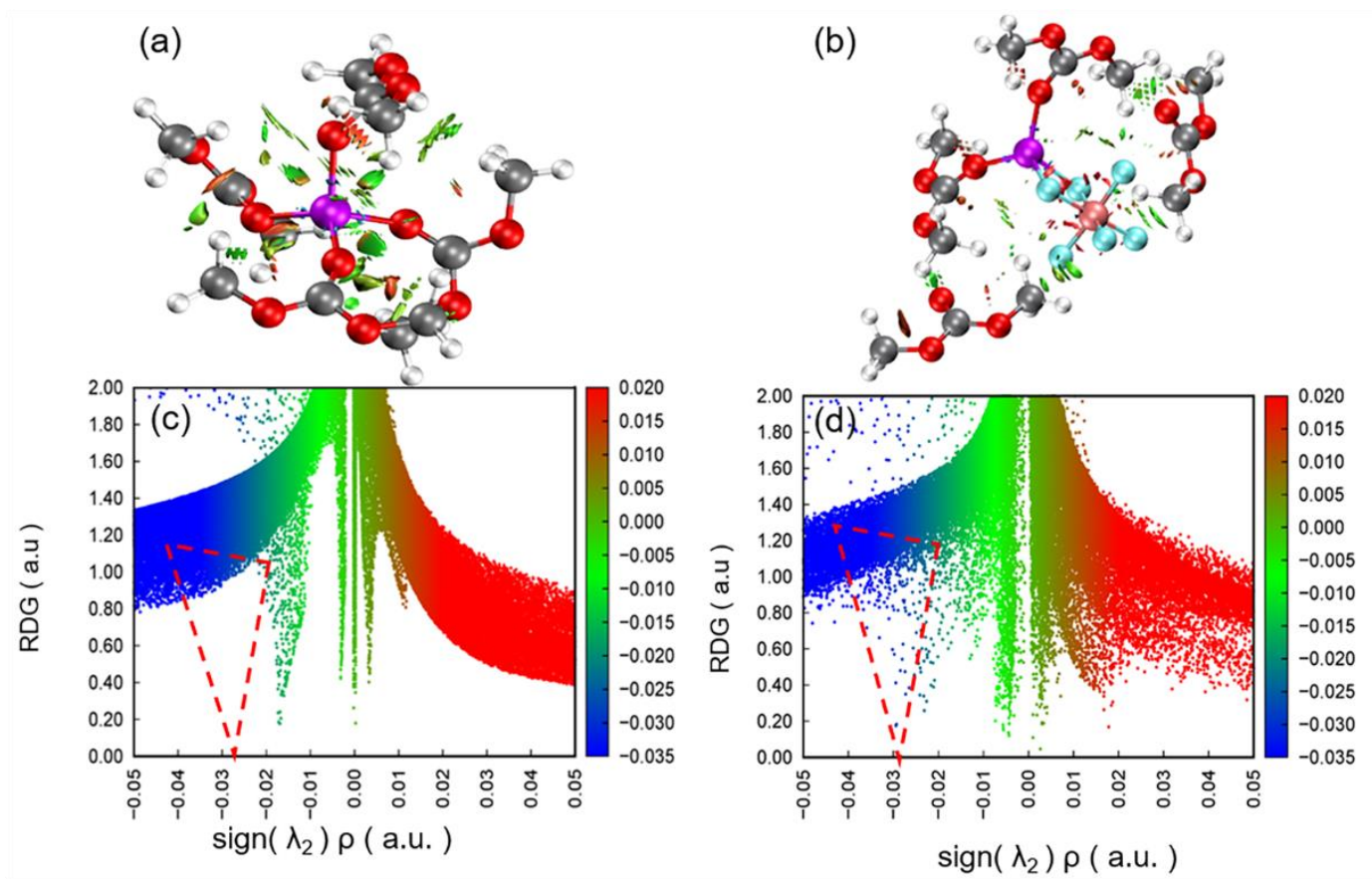

Figure S2. Weak interaction difference between $\mathrm{Li}^{+}(\mathrm{DMC})_{4}$ and $\mathrm{Li}^{+}(\mathrm{DMC})_{4} \mathrm{PF}_{6}{ }^{-}$. (a-b)

Distribution of weak interactions and (c-d) Plots of the reduced density gradient. Blue, green and red denote strong attraction, van der Waals effect and strong mutual exclusion, respectively.

Software of Multiwfn 3.8 combined with VMD1.9.3 was used for Reduced density gradient (RDG) analysis to analyze the weak interaction between $\mathrm{LiPF}_{6}$ and $\mathrm{DMC}$. When RDG analysis shows weak interaction, the spike in the smaller area in the scatter plot would appear. The red triangle shows that the nonbonding interaction increases after $\mathrm{PF}_{6}-$ participates in the solvent structure. 
Table S1. Initial charge, discharge, irreversible capacities and coulombic efficiency of $\mathrm{LiNi}_{0.5} \mathrm{Mn}_{1.5} \mathrm{O}_{4}$ electrodes in different concentrations of $\mathrm{LiPF}_{6} / \mathrm{DMC}$.

\begin{tabular}{ccccc}
\hline $\begin{array}{c}\text { Electrolyte } \\
\text { concentration } \\
\left(\mathrm{mol} \mathrm{L}^{-1}, \mathrm{M}\right)\end{array}$ & $\begin{array}{c}\text { Charge } \\
\text { capacity } \\
\left(\mathrm{mAh} \mathrm{g}^{-1}\right)\end{array}$ & $\begin{array}{c}\text { Discharge } \\
\text { capacity } \\
\left(\mathrm{mAh} \mathrm{g}^{-1}\right)\end{array}$ & $\begin{array}{c}\text { Irreversible } \\
\text { Capacity } \\
\left(\mathrm{mAh} \mathrm{g}^{-1}\right)\end{array}$ & $\begin{array}{c}\text { Coulombic } \\
\text { efficiency } \\
(\%)\end{array}$ \\
\hline 1 & 152.2 & 120.8 & 31.4 & 79.37 \\
5.5 & 169.1 & 136.5 & 32.6 & 80.72 \\
\hline
\end{tabular}

Initial charge, discharge, irreversible capacities and coulombic efficiency of $\mathrm{LiNi}_{0.5} \mathrm{Mn}_{1.5} \mathrm{O}_{4}$ electrodes in different concentrations of $\mathrm{LiPF}_{6} / \mathrm{DMC}$ was performed on the LAND-CT2001A tester (Wuhan, China), the voltage range was $3.5 \sim 5 \mathrm{~V}$. Table S1 shows that highly concentrated electrolyte has better reversibility and higher coulombic efficiency than dilute electrolyte, which means the intercalation/ deintercalation of $\mathrm{Li}^{+}$ions can be carried forward well. 

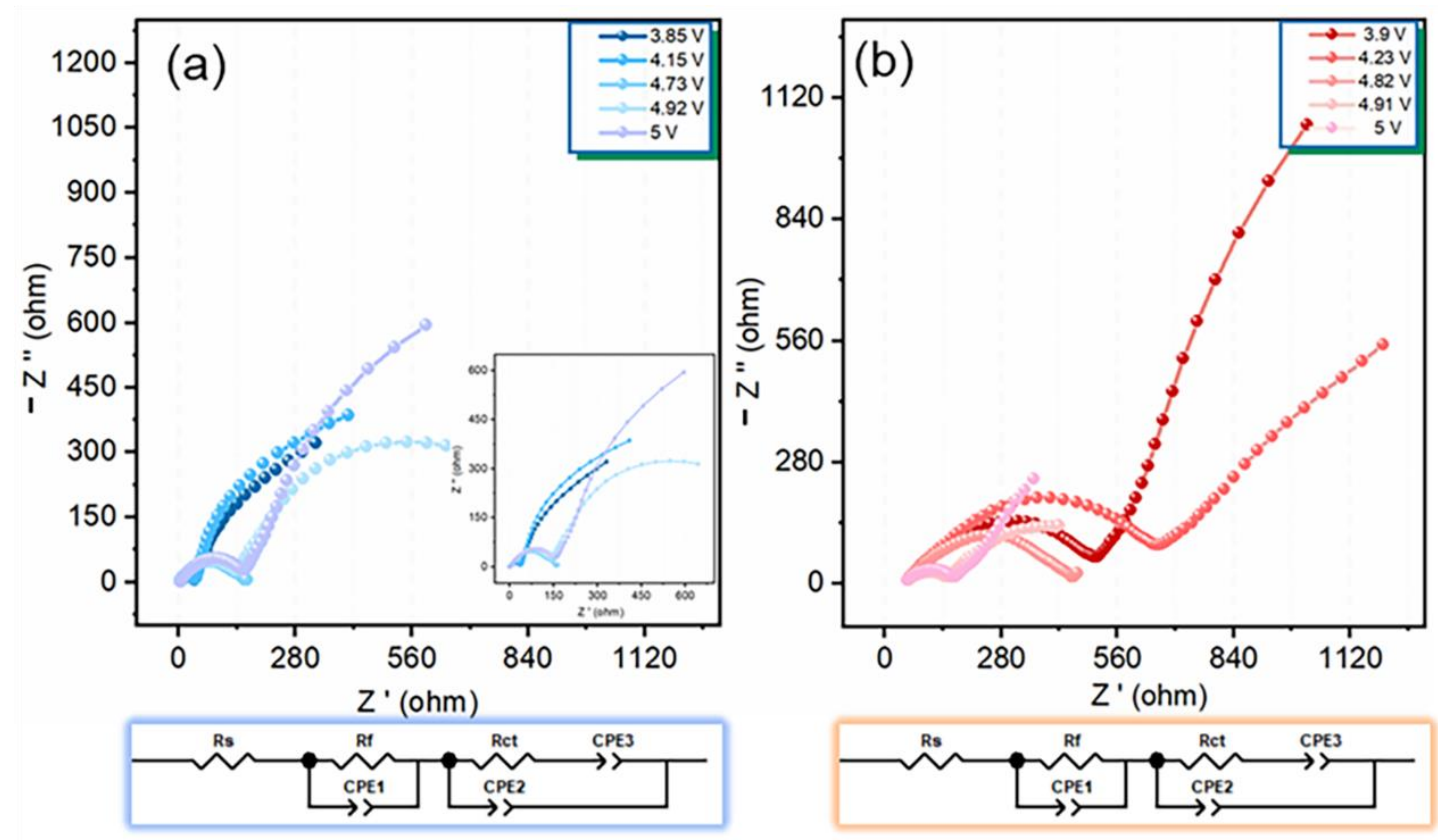

Figure S3. Electrochemical Impedance of the LNMO cathodes at different electrolytes under different voltages. (a) $1 \mathrm{M} \mathrm{LiPF}_{6} / \mathrm{DMC}$ and (b) $5.5 \mathrm{M} \mathrm{LiPF}_{6} / \mathrm{DMC}$.

Table S2. Fitting result of electrochemical impedance data of the LNMO cathodes at different electrolytes under different voltages.

\begin{tabular}{lcccc}
\hline Electrolyte & Potential $(\mathrm{V})$ & $\mathrm{R}_{\mathrm{s}} / \Omega$ & $\mathrm{R}_{\mathrm{f}} / \Omega$ & $\mathrm{R}_{\mathrm{ct}} / \Omega$ \\
\hline & 3.85 & 3.179 & 25.4 & 346.3 \\
& 4.15 & 3.244 & 27.0 & 505.0 \\
$1 \mathrm{M} \mathrm{LiPF} / \mathrm{DMC}$ & 4.73 & 3.364 & 117.8 & 17.19 \\
& 4.92 & 3.063 & 150.9 & 785.0 \\
& 5 & 3.377 & 155.7 & 945.1 \\
\hline $5.5 \mathrm{M} \mathrm{LiPF} / \mathrm{DMC}$ & 3.9 & 45.81 & 153.0 & 309.4 \\
& 4.23 & 46.50 & 195.1 & 358.5 \\
& 4.82 & 49.26 & 262.1 & 108.1 \\
& 4.91 & 49.53 & 99.17 & 105.0 \\
& 5 & 44.65 & 58.28 & 56.12 \\
\hline
\end{tabular}


The test results of the film forming potential of highly concentrated electrolyte and dilute electrolyte from PRIs-EIS and the impedance at each voltage was fitted by ZSimpWin. As shown in Figure S3 and Table S3, the results show that the interfacial impedance $\left(\mathrm{R}_{\mathrm{f}}\right)$ of highly concentrated electrolyte is smaller than that of dilute electrolyte. More detailed instructions are given in the manuscript. 

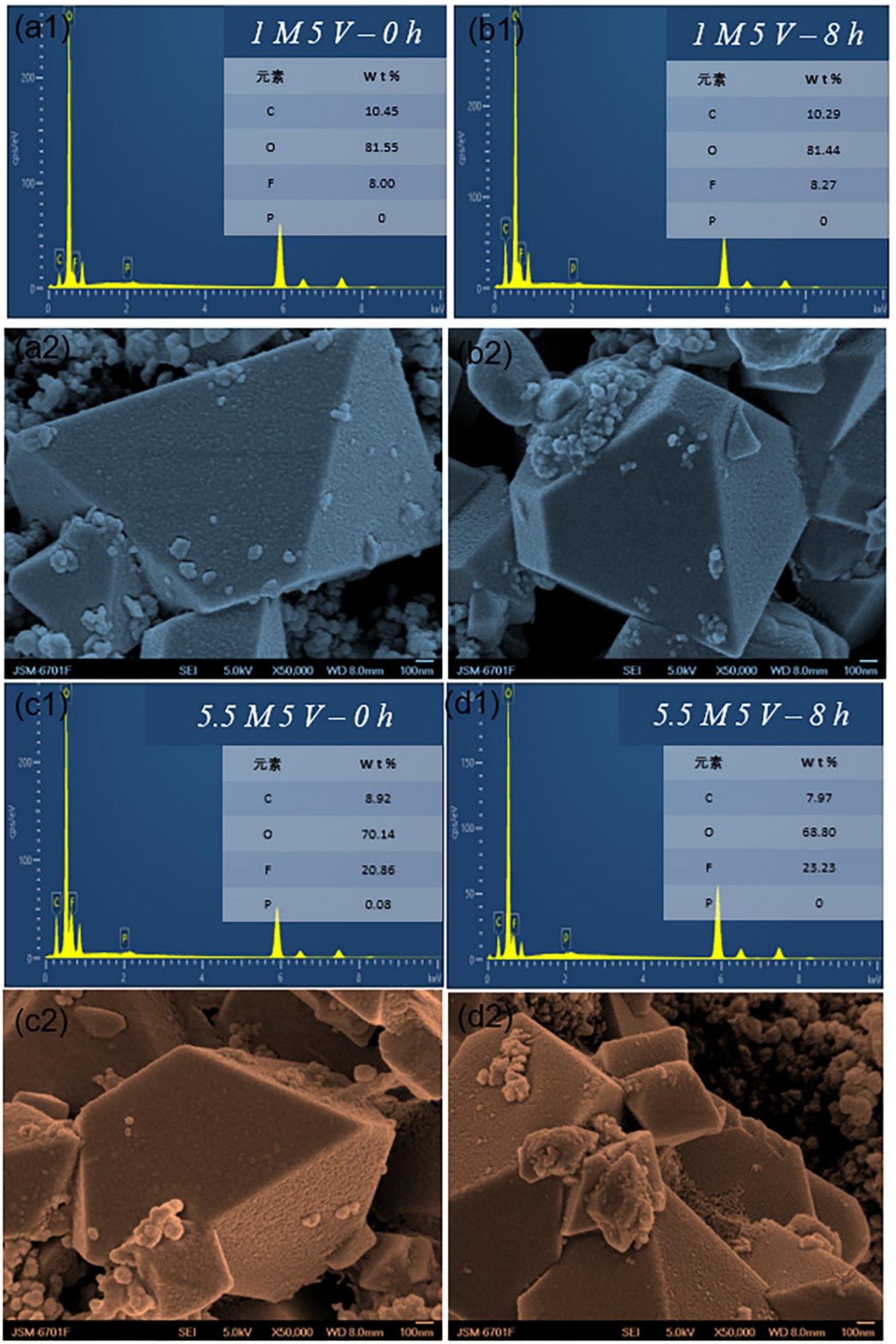

Figure S4. SEM images and EDS of the LNMO electrodes with different concentration electrolytes at static durations of $0 \mathrm{~h}$ and $8 \mathrm{~h}$. (a1-a2) $1 \mathrm{M} \mathrm{LiPF}_{6} / \mathrm{DMC}$ - 
0 h, (b1-b2) $1 \mathrm{M} \mathrm{LiPF}_{6} / \mathrm{DMC}^{-8} \mathrm{~h}$, (c1-c2) $5.5 \mathrm{M} \mathrm{LiPF}_{6} / \mathrm{DMC}^{-0} \mathrm{~h}$, (d1-d2) $5.5 \mathrm{M}$ LiPF $6 / \mathrm{DMC}^{-8} \mathrm{~h}$.

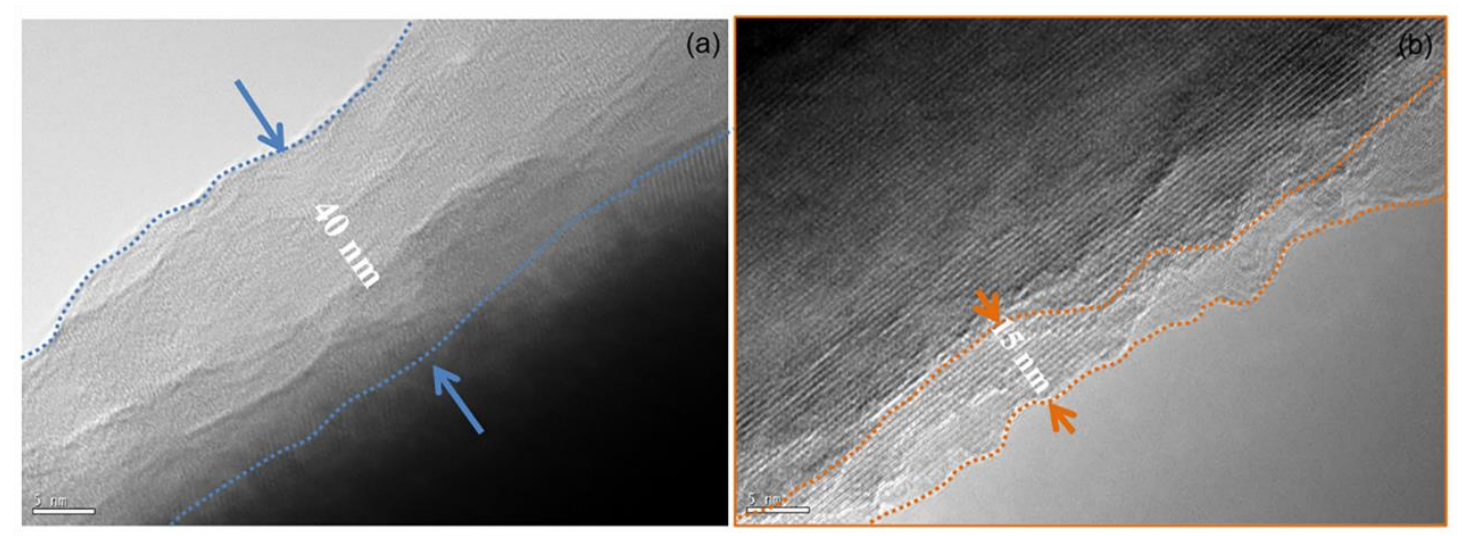

Figure S5. TEM images of the LNMO electrodes with different concentration electrolytes after charging. (a) $1 \mathrm{M} \mathrm{LiPF}_{6} / \mathrm{DMC}$; (b) $5.5 \mathrm{M} \mathrm{LiPF}_{6} / \mathrm{DMC}$

As shown in Figure S4, S5, the results are clearly depicted that highly concentrated electrolyte at high voltage can form a thinner and denser CEI film with high ionic conductivity and low impedance, further affecting the electrochemical performance. 